\title{
Differences between Seated and Standing Low-Speed Treadmill Walking
}

\author{
David K. Brennan, Ph. $D^{1^{*}}$ and Thomas W. Allen, DO, MPH \\ ${ }^{1}$ School of Community Medicine, University of Oklahoma, USA \\ ${ }^{2}$ Sports Medicine, Oklahoma State University, USA

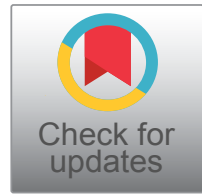

*Corresponding author: David K. Brennan, University of Oklahoma, School of Community Medicine, Tulsa, USA

\begin{abstract}
Objective: The purpose of this study was to compare the Energy Expenditure (EE) during very low-speed (<2.0 mph) treadmill walking while seated to EE during upright treadmill walking.
\end{abstract}

Design: A convenience sample cohort study of nine volunteer participants (4 males; 5 females) $M$ age 63.4 ( \pm 10.5) years performed both seated (MuV) and standing walking (STW), across $0.5 \mathrm{mph}, 1.1$ and $1.5 \mathrm{mph}$ velocities.

Setting: Institutional, University of Oklahoma Human Performance Laboratory in Tulsa.

Participants: Elderly adults with no contra-indications for low speed walking, recruited from the University of Oklahoma staff, faculty and a local YMCA.

Main outcome measures: Differences between MuV and STW $\mathrm{O}_{2}$ Consumption $\left(\mathrm{VO}_{2}\right)$, Rating of perceived exertion $\left(\mathrm{RPE}_{10}\right)$, and heart rate (HR).

Results: Mean HR and $\mathrm{VO}_{2}$ differences between MuV (Seated) and STW (standing) walking at very low intensities were small but statistically significant at $p<0.05$. Effect sizes were moderate to high (0.61-0.85) for VO2 at 0.5 and $1.1 \mathrm{mph}$ respectively and low to moderate $(0.23-0.61)$ for HR and RPE for $1.1 \mathrm{mph}$ speed.

Conclusions: For people unable to stand or walk, the seated treadmill is a suitable alternative to an upright treadmill. Additional studies in larger and more diverse populations are required in order to confirm this studies initial findings to the general population.

Clinical relevance: This form of exercise may have value for those seeking very low intensity (subliminal) exercise while seated at a desk or for those individuals who have a low orthopedic tolerance.

\section{Keywords}

Treadmill walking, Seated walking, $\mathrm{O}_{2}$ consumption, Rating of perceived exertion

\section{Introduction}

For many people who are unable to jog or run, walking is a viable substitute for cardio/pulmonary and leg strengthening exercise. Hindrances to walking, however, such as lower extremity weakness, neuromuscular disorders and vision impairment effect many people. Others have vocations that require sitting at a desk or table for most of the workday are at risk for the negative health effects of inactivity [1-3]. Prolonged sitting has been associated with an increased risk of cardiovascular events [4-6] and may be considered the "New Smoking" [7]. Excessive sitting is positively related to the development of type II diabetes and a major contributor to the high rates of obesity in the general population [8,9]. Some corporate wellness programs permit desk workers and others to work while walking on a low-speed treadmill [5]. Standing desk treadmills are the most popular among participants. However, several drawbacks have limited the wide acceptance of the standing machines including comfort, cost, and size $[2,10]$. The MuV is a small low speed seated treadmill is designed to fit under a work surface or desk. This study examines the physiological differences between seated treadmill and standing walking across three predetermined walking speeds, $0.5 \mathrm{mph}, 1.1 \mathrm{mph}$ and 1.5 $\mathrm{mph}$.

\section{Specific Aims}

This pilot study compared very-low speed walking while sitting (MuV) to very-low speed walking while standing (STW). The Energy Expenditure (EE) of nine physically active adults ( 4 males and 5 females), were

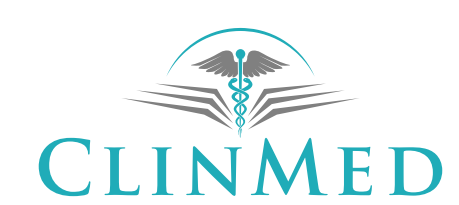

INTERNATIONAL LIBRARY

Citation: Brennan DK, Allen TW (2021) Differences between Seated and Standing Low-Speed Treadmill Walking. Int J Sports Exerc Med 7:206. doi.org/10.23937/2469-5718/1510206

Accepted: November 25, 2021; Published: November 27, 2021

Copyright: (C) 2021 Brennan DK, et al. This is an open-access article distributed under the terms of the Creative Commons Attribution License, which permits unrestricted use, distribution, and reproduction in any medium, provided the original author and source are credited. 
measured, and compared.

Physiological variables included Heart Rate (HR), Expired Air $\left(\mathrm{VO}_{2}\right)$, Cadence (CAD) and Rating of Perceived Exertion $\left(\mathrm{RPE}_{10}\right)$. Hypothesis: Energy Expenditure (EE) during $\mathrm{MuV}^{\mathrm{TM}}$ and STW walking will not be significantly different $(p<0.05)$ across three walking velocities $(0.5$ $\mathrm{mph}, 1.1 \mathrm{mph}$ and $1.5 \mathrm{mph}$ ).

\section{Methods}

A small convenience sample of four physically active males and five physically active females $(M=63.4( \pm$ 10.5) years of age, was recruited from University of Oklahoma Health Sciences Center students, physicians, employees and Tandy YMCA staff and members. This study was approved by the University of Oklahoma Institutional Review Board. Exclusion criterion included; 1) Any yes response on the Physical Activity Readiness Questionnaire (PAR-Q) [11], or 2) Any cardiac, pulmonary, or musculoskeletal contraindications to exercise. All participants were injury free for the past 3 months, and had previous experience walking on a motorized treadmill.

\section{Physiological measures}

Physiological measures for EE included VO2 (ml/ $\mathrm{kg}^{-1} /$ $\min ^{-1}$ ), Heart Rate (HR) (beats/min), Cadence (Steps/ minute $^{-1}$ ) and a subjective Rating of Perceived Exertion $\left(\mathrm{RPE}_{10}\right)$ for both lungs and legs. Metabolic rates were determined by indirect calorimetry using a computerized metabolic system (Parvo Medics, TrueOne 2400, Sandy, UT, USA). Samples of expired gases were collected during walking while sitting and standing. Collection occurred through a one-way breathing valve and tubing that directed flow first through a pneumotach for measurement of volume flow rates, and then into a mixing chamber. Rates of oxygen uptake (VO2) and were determined from the average value during the minute of each five-minute trial. Standing walking tests were performed on a calibrated motorized treadmill (STW). $\mathrm{S}$ seated walking was performed on a calibrated $\mathrm{MuV}^{\mathrm{TM}}$ mini-treadmill. These measures have shown in the past to be stable and reliable variables to compare energy expenditure specifically for walking or running energy expenditure [12-15]. This study compared the individual EE differences between seated walking (MuV) and upright walking (STW). Paired T-Test were performed along with an Omnibus ANOVA. The minimum alpha significance level was set at 0.05 . In order to conduct a power analysis, Cohen's d-statistic values for small $(0.40)$, moderate $(0.60)$, and large $(0.80)$ effects were calculated [16].

\section{Graded Exercise Test (GXT)}

Participants were randomly assigned to one of two groups to control for the ordering effect. After a 2-3minute warm-up/familiarization at a self-selected pace.

Group 1 performed the seated treadmill walking stages first followed by standing treadmill walking. Group 2 began with STW (standing) walking and then performed the MuV walking test. Variables were recorded the last 30 each stage. The test protocol for each group was as follows:

\section{Group 1}

\section{Activity}

Speed Duration

Seated walking Familiarization $0.5-1.0 \mathrm{mph} \quad 2 \mathrm{~min}$

$\begin{array}{lll}\text { Seated walking Stage 1 } & 0.5 \mathrm{mph} & 4 \mathrm{~min} \\ \text { Seated walking Stage 2 } & 1.1 \mathrm{mph} & 4 \mathrm{~min} \\ \text { Seated walking Stage 3 } & 1.5 \mathrm{mph} & 4 \mathrm{~min} \\ \text { Seated recovery Rest } & 0.0 \mathrm{mph} & 2 \mathrm{~min} \\ \text { Standing walking Stage 1 } & 0.5 \mathrm{mph} & 4 \mathrm{~min} \\ \text { Standing walking Stage 2 } & 1.1 \mathrm{mph} & 4 \mathrm{~min} \\ \text { Standing walking Stage 3 } & 1.5 \mathrm{mph} & 4 \mathrm{~min} \\ \text { Standing recovery Rest } & 0.0 \mathrm{mph} & 2 \mathrm{~min}\end{array}$

\section{Group 2}

Standing walking Stage 1

$0.5 \mathrm{mph}$

$4 \mathrm{~min}$

Standing walking Stage 2

$1.1 \mathrm{mph}$

$4 \mathrm{~min}$

Standing walking Stage 3

$1.5 \mathrm{mph}$

$4 \mathrm{~min}$

Standing recovery Rest

$0.0 \mathrm{mph}$

$2 \min$

Seated walking Familiarization

Seated walking Stage 1

0.5-1.0 mph

$2 \min$

Seated walking Stage 2

$0.5 \mathrm{mph}$

$4 \mathrm{~min}$

Seated walking Stage 3

$1.1 \mathrm{mph}$

$4 \mathrm{~min}$

Seated recovery Rest

$1.5 \mathrm{mph}$

$4 \mathrm{~min}$

\section{Results}

Four males and five females, mean Age 63.4 ( \pm 7.41 ), BMI 32.1 ( \pm 10.5), performed MuV and STW portions of the graduated walk test. Assumptions for normal distribution and homogeneity of variance $(\alpha>0.05)$ for VO2, HR, CAD, age and BMI were met. MuV and STW means $( \pm S D$ ) across three walking speeds of $0.5 \mathrm{mph}$, $1.1 \mathrm{mph}$ and $1.5 \mathrm{mph}$ were calculated for VO2, HR, RPE and Cadence mean values and standard deviations are presented in Table 1.

\section{$\mathrm{O}_{2}$ Consumption}

Observed differences in $\mathrm{O}_{2}$ consumption $\left(\mathrm{VO}_{2}\right)$ between MuV and STW walking were small. Seated (MuV) $\mathrm{VO}_{2}$ at $0.5 \mathrm{mph}$ was slightly less than STW at 0.5 $\mathrm{mph}$, Mean difference $=-0.92 \mathrm{ml} / \mathrm{kg}^{-1} / \mathrm{min}^{-1}( \pm 1.0)(\mathrm{Cl}$ $95 \%-1.71,-0.80), t(1,8)=-2.54, p<0.05$ (ES 0.85) as well as $1.1 \mathrm{mph}$ velocity, mean difference $=-1.13 \mathrm{ml} /$ $\mathrm{kg}^{-1} / \mathrm{min}^{-1}( \pm 1.2),(C / 95 \%-2.12,-0.13), t(1,8)=-2.61, p$ $<0.05$ (ES 0.87). At $1.5 \mathrm{mph}, \mathrm{VO}_{2}$ for MuV walking was slightly lower than STW walking, and was not statistically 
Table 1: Resting and Walking Mean, $( \pm \mathrm{SD}) \mathrm{VO}_{2}$, Heart Rate and Cadence for seated (MuV) and standing (TM) Treadmill Walking.

\begin{tabular}{|c|c|c|c|}
\hline Variable & & Mean & $\pm S D$ \\
\hline \multicolumn{4}{|c|}{$\mathrm{VO}_{2} \mathrm{ml} / \mathrm{kg}^{-1} / \mathrm{min}^{-1}$} \\
\hline $0.0 \mathrm{mph}$ & Rest (Seated) & 3.5 & 0.52 \\
\hline \multirow[b]{2}{*}{$0.5 \mathrm{mph}$} & MuV & 4.8 & 0.54 \\
\hline & TM & 5.7 & 1.05 \\
\hline \multirow[b]{2}{*}{$1.1 \mathrm{mph}$} & MuV & 6.2 & 0.90 \\
\hline & TM & 7.3 & 1.28 \\
\hline \multirow[b]{2}{*}{$1.5 \mathrm{mph}$} & Muv & 7.7 & 0.95 \\
\hline & TM & 8.6 & 1.59 \\
\hline \multicolumn{4}{|c|}{ Heart Rate (Beats/min ${ }^{-1}$ ) } \\
\hline $0.0 \mathrm{mph}$ & Rest (Seated) & 69.2 & 9.6 \\
\hline \multirow[b]{2}{*}{$0.5 \mathrm{mph}$} & MuV & 79.2 & 9.0 \\
\hline & TM & 80.4 & 10.3 \\
\hline \multirow[b]{2}{*}{$1.1 \mathrm{mph}$} & MuV & 83.3 & 9.1 \\
\hline & TM & 87.4 & 8.9 \\
\hline \multirow[b]{2}{*}{$1.5 \mathrm{mph}$} & MuV & 89.3 & 10.3 \\
\hline & TM & 91.7 & 9.2 \\
\hline \multicolumn{4}{|c|}{ Cadence (Steps/min ${ }^{-1}$ ) } \\
\hline \multirow[b]{2}{*}{$0.5 \mathrm{mph}$} & MuV & 53.9 & 14.5 \\
\hline & TM & 54.9 & 17.5 \\
\hline \multirow[b]{2}{*}{$1.1 \mathrm{mph}$} & MuV & 75.3 & 9.7 \\
\hline & TM & 70.2 & 13.2 \\
\hline \multirow[b]{2}{*}{$1.5 \mathrm{mph}$} & MuV & 96.0 & 11.7 \\
\hline & TM & 81.4 & 12.9 \\
\hline
\end{tabular}

significant, mean difference $=-0.965 \mathrm{ml} / \mathrm{kg}^{-1} / \mathrm{min}^{-1}( \pm$ 1.54), (Cl 95\% -2.14, 0.23), $t(1,8)=-1.85, p>0.05$ (ES $0.72)$. Figure 1 compares mean resting $\mathrm{VO}_{2}(3.46 \mathrm{ml} /$ $\mathrm{kg}^{-1} / \mathrm{min}^{-1}$ ) with $\mathrm{VO}_{2}$ for both MuV and STW conditions across the three designated walking velocities. When compared to resting values, $\mathrm{O}_{2}$ consumption was significantly greater $(p<0.001)$ for both MuV, mean 4.8 ( \pm 0.53$), 6.2( \pm 0.90), 7.7( \pm 0.53) \mathrm{ml} / \mathrm{kg}^{-1} / \mathrm{min}^{-1}$ and STW conditions, mean 5.7 ( \pm 1.05$), 7.3$ ( \pm 1.28$), 8.7$ ( \pm 1.59 ) $\mathrm{ml} / \mathrm{kg}^{-1} / \mathrm{min}^{-1}$ across $0.5,1.1$ and $1.5 \mathrm{mph}$ walking speeds respectively (Figure 2 ).

\section{Heart Rate}

Heart Rate (HR) for MuV at walking speeds of $1.1 \mathrm{mph}$ was significantly less than STW mean difference $=-3.7$ beats/min $( \pm 3.4)(C l-6.4,-1.1), t(1,8)=3.28, p<0.05$ (ES 0.61). HR for STW walking at $1.5 \mathrm{mph}$ was lower for MuV compared to STW and was statistically but not clinically significant, Mean difference $=-3.7$ beats $/ \mathrm{min}( \pm 3.4)(\mathrm{Cl}$ -6.4, -1.1), $t(1,8)=-2.56, p<0.05$ (ES 0.39) (See Table $2)$. When compared to resting $H R$, walking $H R$ values were significantly greater $(p<0.01)$ for both MuV, mean 10.1 ( \pm 6.8$), 14.2 .2( \pm 7.7), 20.2( \pm 8.8)$ beats $/ \mathrm{min}^{-1}$ and STW conditions, mean $11.3( \pm 8.7), 18.0( \pm 7.7), 22.7$ ( \pm 7.8) beats per/min $\mathrm{m}^{-1}$ across $0.5,1.1$ and $1.5 \mathrm{mph}$ walking speeds respectively.

\section{RPE and Cadence}

There were no statistically significant differences between MuV and STW conditions for Rating of Perceived Exertion (RPE) $(p>0.05)$ for both lungs and

10

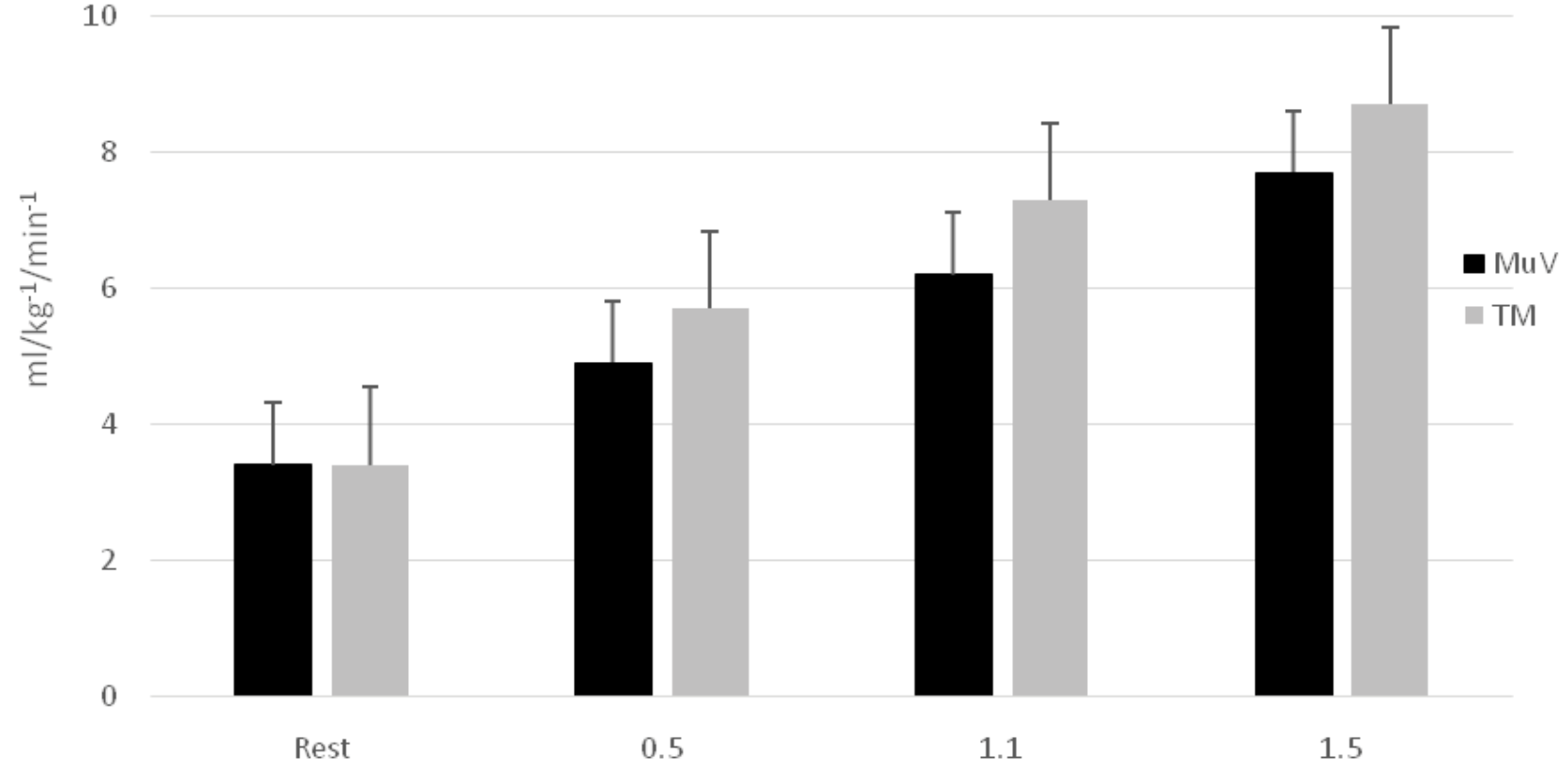

Miles Per Hour

Figure 1: Mean $\mathrm{VO}_{2}$ and SEE for MuV and TM walking. 


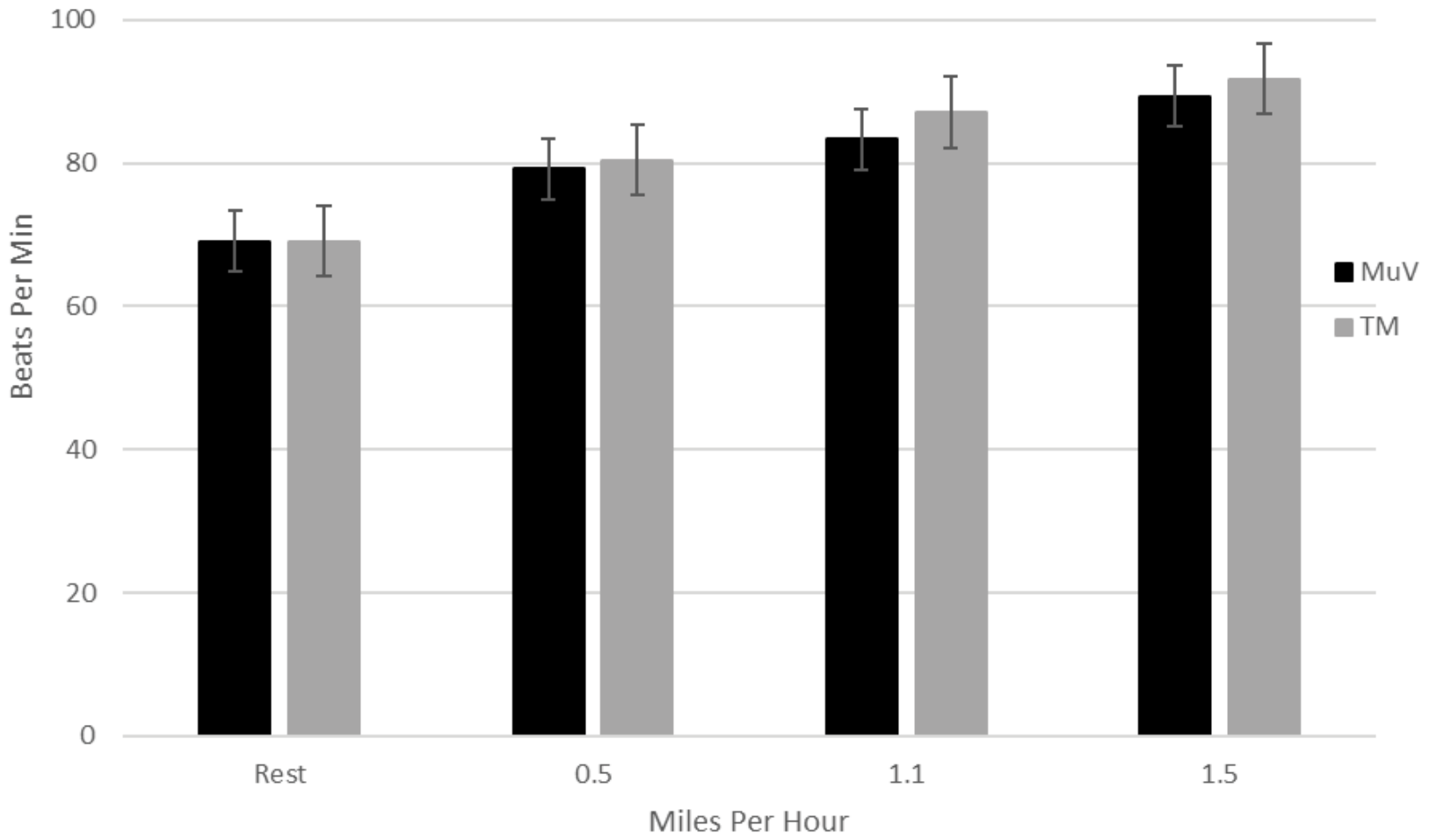

Figure 2: Mean Heart Rate and SEE for MuV and TM walking.

Table 2: Mean Differences, SD, Cls and effect size between MuV and TM for $\mathrm{O}_{2}$ Uptake $\left(\mathrm{VO}_{2}\right)$ in $\mathrm{ml} / \mathrm{kg}^{-1} / \mathrm{min}^{-1}, \mathrm{Heart} \mathrm{Rate}(\mathrm{HR})$ beats/min, Rating of Perceived Exertion $\left(\mathrm{RPE}_{10}\right)$ and Cadence (CAD) steps/min.

\begin{tabular}{|c|c|c|c|c|}
\hline & Mean Dif. & \pm SD & Cl $95 \%$ & ES $^{\wedge}$ \\
\hline \multicolumn{5}{|l|}{$\mathrm{VO}_{2}$} \\
\hline (0.5 mph) & -0.92 & 1.08 & $(-1.75,0.08)$ & $0.85^{*}$ \\
\hline (1.1 mph) & -1.13 & 1.29 & $(-2.13,-0.13)$ & $0.87^{*}$ \\
\hline (1.5 mph) & -0.95 & 1.54 & $(-2.14,0.22)$ & 0.61 \\
\hline \multicolumn{5}{|l|}{ HR } \\
\hline (0.5 mph) & -1.22 & 5.19 & $(-5.21,2.76)$ & 0.23 \\
\hline (1.1 mph) & -3.77 & 3.45 & $(-6.43,-1.12)$ & $0.61^{*}$ \\
\hline (1.5 mph) & -2.44 & 2.83 & $(-4.62,-0.26)$ & $0.39^{*}$ \\
\hline \multicolumn{5}{|l|}{$R_{P E}$ lungs } \\
\hline (0.5 mph) & 0.44 & 0.72 & $(-0.11,1.0)$ & 0.61 \\
\hline (1.1 mph) & 0.33 & 0.70 & $(-0.21,0.87)$ & 0.47 \\
\hline (1.5 mph) & 0.22 & 0.66 & $(-0.29,0.73)$ & 0.33 \\
\hline \multicolumn{5}{|l|}{$\mathbf{R P E}_{\text {legs }}$} \\
\hline (0.5 mph) & 0.66 & 1.11 & $(-0.19,1.52)$ & 0.59 \\
\hline (1.1 mph) & 1.11 & 1.53 & $(0.06,0.07)$ & 0.72 \\
\hline (1.5 mph) & 1.33 & 2.73 & $(-0.77,3.43)$ & 0.48 \\
\hline \multicolumn{5}{|l|}{ CAD } \\
\hline (0.5 mph) & -1.00 & 7.25 & $(-6.57,4.57)$ & 0.13 \\
\hline (1.1 mph) & 5.11 & 11.92 & $(-4.05,14.27)$ & 0.42 \\
\hline (1.5 mph) & 14.56 & 17.1 & $(0.92,28.1)$ & 0.82 \\
\hline
\end{tabular}

Significant ${ }^{*} p<0.05,{ }^{\wedge}$ Cohens D Effect Size (ES) 
legs across all three walking velocities. No significant differences in cadence were found between MuV and STW conditions for 0.5 and $1.1 \mathrm{mph}$ walking speeds ( $p$ $>0.05)$. However, higher cadences were observed for MuV condition at $1.5 \mathrm{mph}$ speeds when compared to the STW condition and these differences were statistically significant, mean difference $=14.5$ steps $/ \mathrm{min}( \pm 17.7)(\mathrm{Cl}$ $0.94,28), t(1,8)=-2.47, p<0.04$ (ES 0.82).

\section{Conclusion}

At very low intensities energy expenditure (HR and $\mathrm{VO}_{2}$ ) for standing walking was slightly higher than seated walking and were statistically significant $(p<0.05)$. Effect sizes were moderate to high for $\mathrm{VO}_{2}$ at 0.5 and 1.1 $\mathrm{mph}$ respectively and low to moderate for HR and RPE at $1.1 \mathrm{mph}$. These findings align with results reported by previous studies. Wang, et al., 2018 explored the difference between resting seated and standing energy expenditure and reported a $16.8 \%$ greater mean $\mathrm{VO}_{2}$ for standing $\left(M=4.04 \pm 0.38 \mathrm{ml} / \mathrm{kg}^{-1} / \mathrm{min}^{-1}\right)$ resting energy when compared to resting $\mathrm{VO}_{2}$ for sitting $(M=4.72 \pm 0.42$ $\left.\mathrm{ml} / \mathrm{kg}^{-1} / \mathrm{min}^{-1}\right) p<0.01$ [3]. Ludlow, et al. also reported modest differences between with mean $\mathrm{VO}_{2}$ measures of $3.16 \pm 0.08 \mathrm{ml} / \mathrm{kg}^{-1} / \mathrm{min}^{-1}$ and $3.51 \pm 0.08$ for seated and standing values respectively [17].

For this current study, VO and HR values were statistically higher across $0.5,1.1$ and $1.5 \mathrm{mph}$ walking for both MuV and STW conditions when compared to resting values. Higher cadences observed for the MuV condition compared to the standing $1.5 \mathrm{mph}$ walking speeds is likely due participants adopting a shorter stride pattern in order to accommodate the higher treadmill velocity. Seated treadmill walking (MuV) may have value for those seeking "subliminal exercise" while seated at a desk or for those individuals who have a low orthopedic tolerance or other disabilities preventing them from walking while standing. This current study should guide future, cohort studies in order to determine if MuV walking at very low intensity levels would be a valid surrogate for low-intensity treadmill walking. Additional research should focus on developing appropriate walking speeds for "subliminal exercise" in larger more diverse populations.

\section{Conflicts of Interest and Source of Funding}

The authors acknowledge the technical support of On the $\mathrm{MuV}^{\mathrm{TM}}$ and for suppling seated treadmills used in this study. There are currently no conflict of interests associated with the authors and On the MuV ${ }^{\mathrm{TM}}$.

\section{References}

1. Carr LJ, Walaska KA, Marcus BH (2012) Feasibility of a portable pedal exercise machine for reducing sedentary time in the workplace. Br J Sports Med 46: 430-435.

2. Straker L, Levine J, Campbell A (2009) The effects of walking and cycling computer workstations on keyboard and mouse performance. Hum Factors 51: 831-844.
3. Wang M, Song Y, Baker JS, Fekete G, Gu Y (2018) Sitting to standing postural changes: Energy expenditure and a possible mechanism to alleviate sedentary behavior. Physiology International 105: 157-165.

4. McAlpine DA, Manohar CU, McCrady SK, Hensrud D, Levine JA (2007) An office-place stepping device to promote workplace physical activity. Br J Sports Med 41: 903-907.

5. Shrestha N, Kukkonen-Harjula KT, Verbeek JH, ljaz S, Hermans V, et al. (2018) Workplace interventions for reducing sitting at work. Cochrane Database of Syst Rev 6: CD010912.

6. Thompson WG, Foster RC, Eide DS, Levine JA (2008) Feasibility of a walking workstation to increase daily walking. Br J Sports Med 42: 225-228.

7. Baddeley BS, Sornalingam S, Cooper M (2016) Sitting is the new smoking: where do we stand? Br J Gen Pract 66: 258.

8. Wilmot EG, Edwardson CL, Achana FA, Davies MJ, Gorely T, et al. (2012) Sedentary time in adults and the association with diabetes, cardiovascular disease and death: systematic review and meta-analysis. Diabetologia 55: 2895-2905.

9. John D, Thompson DL, Raynor H, Bielak K, Rider B, et al. (2011) Treadmill workstations: a worksite physical activity intervention in overweight and obese office workers. J Phys Act Health 8: 1034-1043.

10. Funk RE, Taylor ML, Creekmur CC, Ohlinger CM, Cox RH, et al. (2012) Effect of walking speed on typing performance using an active workstation. Percept Mot Skills 115: 309318.

11. Thomas S, Reading J, Shephard RJ (1992) Revision of the physical activity readiness questionnaire (PAR-Q). Can J Sport Sci 17: 338-345.

12. Aitken JC, Thompson J (1988) The respiratory V02/VCO2 exchange ratio during maximum exercise and its use as a predictor of maximum oxygen uptake. Eur J Appl Physiol Occup Physiol 57: 714-719.

13. Borg GA (1982) Psychophysical bases of perceived exertion. Med Sci SportsExerc 14: 377-381.

14. Coyle EF (1995) Integration of the physiological factors determining endurance performance ability. Exerc Sport Sci Rev 23: 25-63.

15. Hill A, Lupton H (1923) Muscular exercise, lactic acid, and the supply and utilization of oxygen. QJM: An International Journal of Medicine 135-171.

16. Cohen J (1988) Statistical power analysis for the behavioral sciences. ( $2^{\text {nd }}$ edn), Á/L. Erbaum Press, Hillsdale, NJ, USA.

17. Ludlow LW, Weyand PG (2017) Walking economy is predictably determined by speed, grade, and gravitational load. J Appl Physiol 123: 1288-1302. 